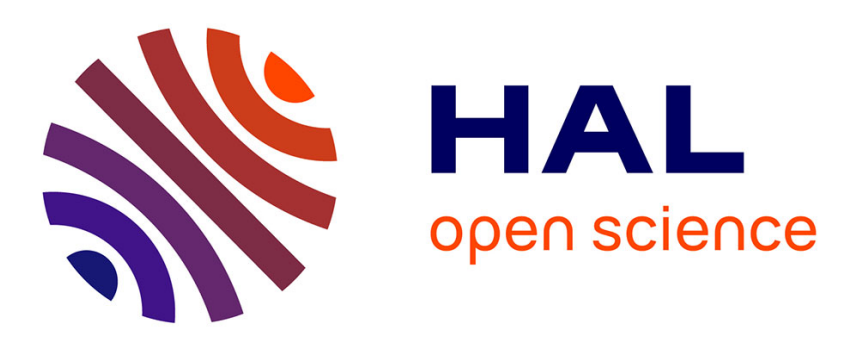

\title{
Temperature dependence of internal bandwidths in plastic adamantane by Raman light scattering
}

\author{
Ph. Depondt, M. Debeau, R.M. Pick
}

\section{To cite this version:}

Ph. Depondt, M. Debeau, R.M. Pick. Temperature dependence of internal bandwidths in plastic adamantane by Raman light scattering. Journal de Physique Lettres, 1984, 45 (13), pp.685-691. 10.1051/jphyslet:019840045013068500 . jpa-00232398

\section{HAL Id: jpa-00232398 https://hal.science/jpa-00232398}

Submitted on 1 Jan 1984

HAL is a multi-disciplinary open access archive for the deposit and dissemination of scientific research documents, whether they are published or not. The documents may come from teaching and research institutions in France or abroad, or from public or private research centers.
L'archive ouverte pluridisciplinaire HAL, est destinée au dépôt et à la diffusion de documents scientifiques de niveau recherche, publiés ou non, émanant des établissements d'enseignement et de recherche français ou étrangers, des laboratoires publics ou privés. 
Classification

Physics Abstracts

$63.50-78.30$

\title{
Temperature dependence of internal bandwidths in plastic adamantane by Raman light scattering
}

\author{
Ph. Depondt, M. Debeau and R. M. Pick \\ Département de Recherches Physiques (*), Université P. et M. Curie, \\ 4, place Jussieu, 75230 Paris Cedex 05, France
}

(Reçu le 25 janvier 1984, révisé le 2 mai, accepté le 14 mai 1984)

\begin{abstract}
Résumé. - La phase à désordre d'orientation de l'adamantane (208 K-541 K) a été étudiée par diffusion Raman de $209 \mathrm{~K}$ à $500 \mathrm{~K}$. La bande de vibration à $1220 \mathrm{~cm}^{-1}$ de symétrie E a été enregistrée avec les symétries $E_{g}$ et $F_{2 g}$. Les spectres $E_{g}$, dus aux molécules ordonnées, sont élargis par un effet de temps de résidence. Les spectres $F_{2 \mathrm{~g}}$, correspondant aux molécules en cours de réorientation, pourraient être attribués à la modification de la vibration interne par l'environnement pendant la rotation.
\end{abstract}

\begin{abstract}
The ODIC phase of adamantane (208 K-541 K) was studied by Raman light scattering between $209 \mathrm{~K}$ and $500 \mathrm{~K}$. The $1220 \mathrm{~cm}^{-1}$, E symmetry, vibrational line was recorded with $\mathrm{E}_{\mathrm{g}}$ and $\mathrm{F}_{2 \mathrm{~g}}$ symmetries. The $\mathrm{E}_{\mathrm{g}}$ spectra, due to ordered molecules, are broadened by a residence time effect. The $F_{2 g}$ spectra, which correspond to molecules as they rotate, could be attributed to the modification of the internal vibration by the environment during the molecular reorientations.
\end{abstract}

\section{Introduction.}

We study here adamantane $\left(\mathrm{C}_{10} \mathrm{H}_{16}\right)$ in a state usually referred to as plastic or ODIC (Orientational Disorder In Crystals), that is, in a situation in which the centres of mass of the molecules form a lattice (FCC in the case of adamantane) but the molecules display orientational disorder and undergo frequent reorientations. In this state, the tetrahedric adamantane molecule tends to rest in its cubic lattice in such a way that its three and fourfold symmetry axes are parallel to the three and fourfold axes respectively, of the crystal [1]. Neutron scattering experiments [2] show :

1) that the molecules undergo mostly $90^{\circ}$ reorientations around their fourfold axes ;

2) that, even in the relatively small range of temperatures at which the experiments were performed, the residence time between reorientations decreases rapidly.

Positron annihilation experiments [3] between room temperature and the melting point show a drastic increase of the concentration of vacancies in the crystal (which are partly linked to the reorientations of the molecules).

$\left(^{*}\right)$ Laboratoire associé au C.N.R.S., $n^{0} 71$. 
One could then expect an important variation with temperature of the rotational contributions to Raman spectra. We describe in this paper such an experiment performed on the $1220 \mathrm{~cm}^{-1}$ internal mode of adamantane, with molecular E symmetry.

\section{Experiments.}

Several technical problems have to be solved in order to be able to perform the experiments. The vapour pressure of adamantane is fairly high $(0.1 \mathrm{mmHg}$ at room temperature, 1.8 atm at $\left.225^{\circ} \mathrm{C}[4]\right)$ with the following consequences :

a) in a light scattering experiment, the incident beam tends to ruin the surface of the sample by a local heating which causes a transport process similar in principle to that used in vapour growth techniques $[5,6]$;

b) as the temperature increases, the sublimation process becomes so rapid that the sample simply disappears before the experiment is completed.

Problem a) had already been partially solved in a room temperature Brillouin scattering experiment [1] by keeping the sample in water. By doing this, one

- reduces the surface effects by index matching

- substitutes a transport in solution to the vapour transport. This is an improvement only if the solubility is small.

Consequently alcohol was substituted to water between -64 and $25^{\circ} \mathrm{C}$, glycerol between 25 and $75^{\circ} \mathrm{C}$ and polyethyleneglycol 2000 (PEG 2000) between 75 and $225^{\circ} \mathrm{C}$ [7]. We checked that the results did not depend on the liquid at temperatures at which two different liquids could be used.

Problem $b$ ) still remained as the liquid does not prevent the formation of bubbles of vapour. This was taken care of by enclosing the sample and liquid in an airtight pyrex cell, which in turn is set on a sample holder especially designed to resist the pressure.

The $1220 \mathrm{~cm}^{-1}$ [8] line was recorded between $209 \mathrm{~K}$ and $498 \mathrm{~K}\left(-64{ }^{\circ} \mathrm{C}\right.$ and $\left.225^{\circ} \mathrm{C}\right)$. Both crystal $\mathrm{E}_{\mathrm{g}}$ and $\mathrm{F}_{2 \mathrm{~g}}$ symmetries [9] were used.

\section{Results and treatment.}

Typical spectra are shown on figure 1. At this stage, they have already been subjected to a digital filter which reduces markedly the noise without altering the bandwidth as has been checked by using various steplengths.

The $E_{\mathrm{g}}$ spectra are narrow and fairly intense and sided by two other lines at 1195 and $1240 \mathrm{~cm}^{-1}$, the origin of which is unknown at present, although they would seem to persist in the low temperature ordered phase [10]. A Lorentz function was fitted to the central line. The resulting half widths at half maximum $\left({ }^{1}\right)$ are shown on figure 2.

The $\mathrm{F}_{2 \mathrm{~g}}$ spectra are broader and less intense (from 2 to $5 \%$ of the $\mathrm{E}_{\mathrm{g}}$ spectra), but their most interesting feature is their asymmetry which made their fitting by a single Lorentzian impossible. On the contrary, they could be resolved, by a two Lorentzian fit, into two contributions which had neither the same frequency nor the same width. Two remarks were then made :

- at each temperature, the narrower contribution had approximately the same frequency and width as the corresponding $\mathrm{E}_{\mathrm{g}}$ spectrum; dent.

- the intensity ratio between the narrow and broad contributions was mainly sample depen-

( $\left.{ }^{1}\right)$ The elastic scattering peak was recorded $\left(\mathrm{HWHM} \simeq 0.6 \mathrm{~cm}^{-1}\right)$ and introduced in the fit by convolution with the Lorentz function in order to account for the broadening by the spectrometer. Consequently the computed HWHMs do not have to be corrected for instrumental effects. 

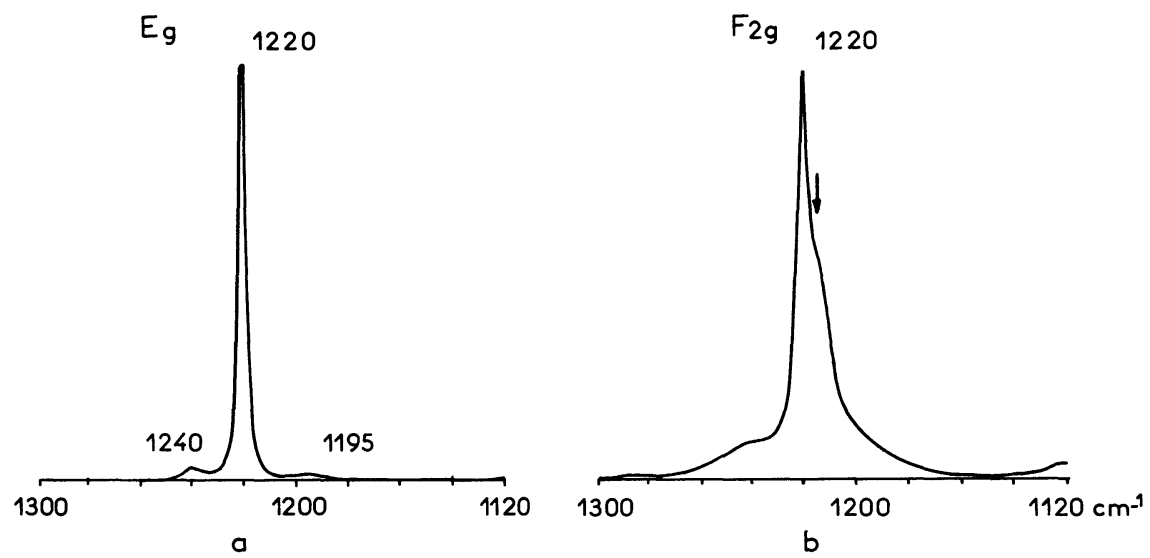

Fig. 1. - Typical room temperature spectra of the E molecular symmetry line at $1220 \mathrm{~cm}^{-1}$. a) $\mathrm{E}_{\mathrm{g}}$ symmetry relative to the crystal; $b$ ) $\mathrm{F}_{2 \mathrm{~g}}$ symmetry relative to the crystal. The arrow points to the effective $\mathrm{F}_{2 \mathrm{~g}}$ rotational peak. Intensity units are arbitrary and unrelated between $a$ ) and $b$ ).

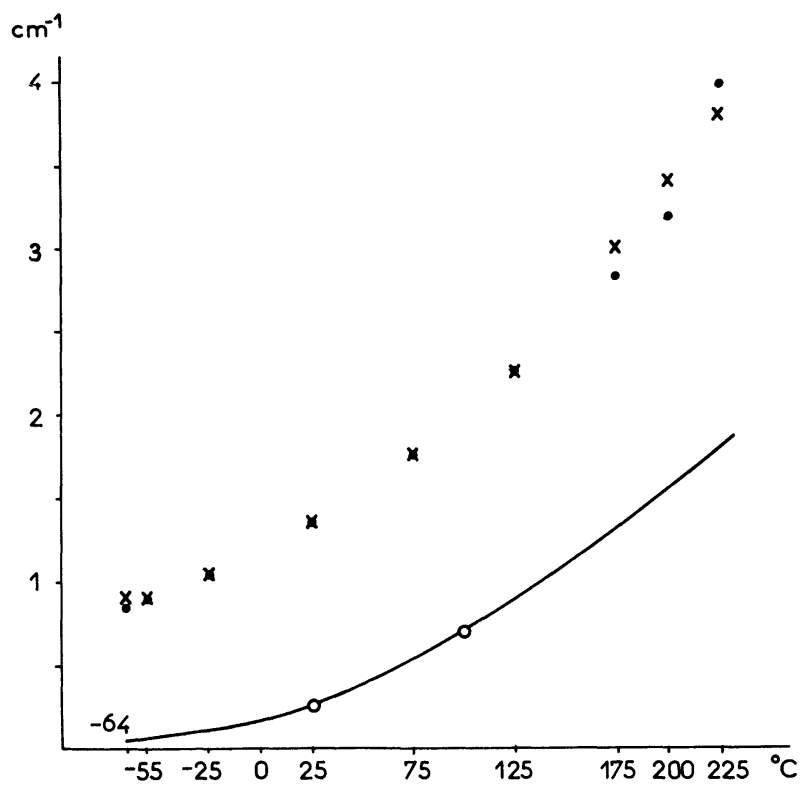

Fig. 2. - HWHM of the $\mathrm{E}_{\mathrm{g}}$ spectra versus temperature. Full circles refer to the VV spectra [9] and crosses to the $\mathrm{HH}$ spectra. The difference between them gives a measure of accuracy. Open circles refer to neutron scattering results [2].

It was thus concluded that the narrow contribution was simply an optical leak of the $\mathrm{E}_{\mathrm{g}}$ spectrum, while the broad one was the actual $F_{2 g}$ spectrum. Another two Lorentzian fit was then performed with the width of the narrow Lorentz function set at the value given by the $\mathrm{E}_{\mathrm{g}}$ spectrum.

This practically did not alter the quality of the agreement between a recorded spectrum and a computed one and an example is given on figure 3 . The resulting $F_{2 g}$ HWHM and distance between the $E_{g}$ and $F_{2 g}$ peaks [11] are shown on figure 4. 


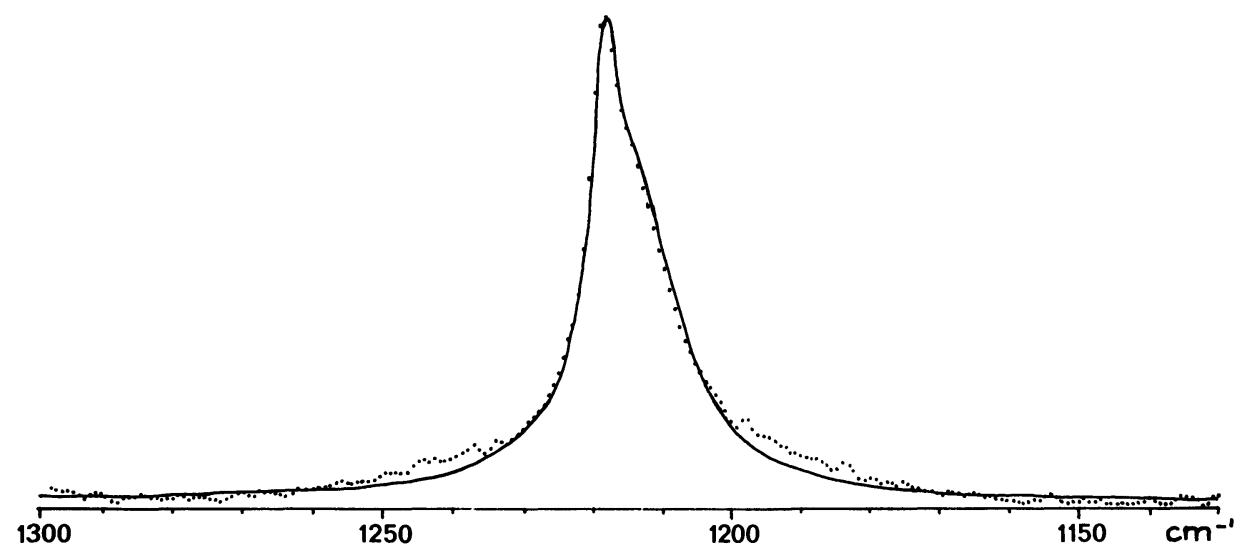

Fig. 3. - Experimental $F_{2 g}$ spectrum (dots) and the two Lorentzian fit (full line) at $75^{\circ} \mathrm{C}$. The intensity unit is arbitrary. The distance between two points is $0.7 \mathrm{~cm}^{-1}$. Remnants of the two side bands noted in the $E_{\mathrm{g}}$ spectra are visible. The one Lorentzian fit of the $E_{\mathrm{g}}$ spectra is of a better quality.

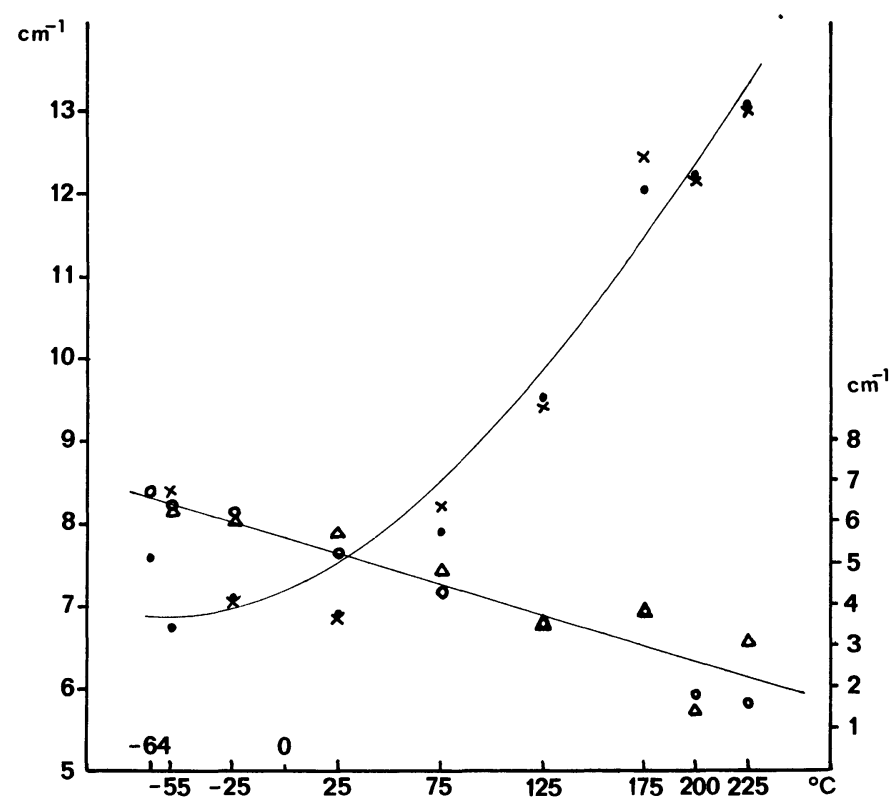

Fig. 4. - HWHM of the $\mathrm{F}_{2 \mathrm{~g}}$ spectra (lefthand scale; closed circles : HV ; crosses : VH) and distance between $E_{g}$ and $F_{2 g}$ peaks (righthand scale ; open circles : $H V$; triangles : $V H$ ). The $F_{2 g}$ spectrum is very weak at temperatures below $-50^{\circ} \mathrm{C}$. At $T=-64^{\circ} \mathrm{C}$ it could not be measured with $\mathrm{VH}$ polarization. The lines are only guides for the eye.

\section{Discussion.}

4.1. - The results presented in section 3 are somewhat unusual as the HWHM are quite different in the two symmetries, for one thing and the peaks do not coincide for another. Such a situation has not been reported up to now except at one temperature in the case of cyano-adamantane [12]. 
Although it is not the purpose of this letter to provide a thorough interpretation of the results, we shall offer a tentative explanation of them.

As pointed out in part 1 , the adamantane molecule rests most of the time in one of two equiprobable equilibrium positions so that its three fourfold axes are parallel to the fourfold axes of the crystal. The projection of the molecular Raman tensor on the crystal axes is then purely diagonal, so that, in this configuration, the $\mathrm{E}$ vibration contributes only to the $\mathrm{E}_{\mathrm{g}}$ spectrum. Therefore the $\mathrm{F}_{2 \mathrm{~g}}$ spectrum results from the short time when the molecule is reorienting and the above symmetry rule does not apply.

4.2. - As the $\mathrm{E}_{\mathrm{g}}$ spectra relate to immobile molecules, the rotational contribution to their bandwidth can be attributed only to a residence time effect : as long as a molecule rests at the bottom of its potential well, it vibrates with frequency $\omega_{0}$. During a reorientation, this molecule feels a different environment, as it must overcome a potential barrier, and thus vibrates with frequency $\omega_{0}+\delta \omega(\Omega)$. When it reaches another equivalent potential well, it resumes its vibration with frequency $\omega_{0}$. This appears as an interruption of the vibration $\omega_{0}$ by reorientations [13].

This effect alone is, however, unable to explain the measured bandwidth (for which the errors are certainly less than $0.5 \mathrm{~cm}^{-1}$ ) and its thermal evolution : if one extrapolates the lifetimes measured by neutron scattering at $301 \mathrm{~K}$ and $373 \mathrm{~K}$ [2], to the whole temperature range of our experiments, one finds that the contribution of the residence time effect to the Raman width is negligible at $209 \mathrm{~K}$ and amounts only to $2 \mathrm{~cm}^{-1}$ at $498 \mathrm{~K}$ (Fig. 2). The additional width can be due to many causes, among which we can point out the following three :

- the coupling between two neighbouring molecules vibrating at the same frequency can affect the frequency of a molecule at rest when the second is rotating. This would act as a dephasing lifetime and cause an apparent decrease of the lifetime by a factor up to 12 , depending on the efficiency of this coupling;

- the orientational disorder of the neighbouring molecules can cause an inhomogeneous broadening by shifting slightly the vibrational frequency of the individual molecules at rest ;

- the vibrational lifetime of the mode is non infinite, due to intra- and intermolecular anharmonicities.

4.3. - As shown in section 4.1, the $\mathrm{F}_{2 \mathrm{~g}}$ spectra of the $\mathrm{E}$ line relate to a reorientating molecule. In a theory in which the rotational broadening is a consequence of the rotation of the dielectric tensor attached to a vibrating molecule $[14,15]$, one expects :

a) the peaks in both polarizations to have the same frequency;

$b$ ) in the case of a $2 \pi / n$ reorientation related to free rotations, the bandwidth to be roughly equal to $\frac{n}{(2 \pi)^{2}} \sqrt{\frac{k T}{I}}$ and thus to vary approximately as $\sqrt{T}$.

Neither condition $(a)$, as shown in 4.2 , nor $(b)$ (Table I) is fulfilled.

The existence of a possible frequency shift has already been accounted for in section 4.2 when it was explained that, as a molecule reorients, it feels a different environment and thus vibrates at another frequency. We suggest that the observed width is caused by a dynamical inhomogeneous broadening effect. Inhomogeneous broadening usually results from the fact that the molecules feel a variety of environments due to the disorder, and vibrate with a distribution of frequencies [16]. In our case, it is a dynamical effect as it is caused by the rotation of the molecule itself : as a molecule rotates it overcomes a potential barrier and its internal vibration is thus continuously altered as it rotates. This alteration depends on the height of the potential barrier, and with increasing temperature, higher and higher barriers can be overcome leading to more and more important alterations of the vibrational frequency. Such effects could explain 
Table I.

\begin{tabular}{cccccc}
$T$ & $\frac{4}{(2 \pi)^{2}} \sqrt{\frac{k T}{I}}$ & HWHM & HWHM & $\frac{\text { HWHM }}{\sqrt{T}}$ & $\frac{\text { HWHM }}{\sqrt{T}}$ \\
$\mathrm{~K}$ & $\mathrm{~cm}^{-1}$ & $\mathrm{HV} \mathrm{cm}$ & $\mathrm{VH} \mathrm{cm}^{-1}$ & $\mathrm{HV} \mathrm{cm}^{-1} \mathrm{~K}^{-1 / 2}$ & $\mathrm{VH} \mathrm{cm}^{-1} \mathrm{~K}^{-1 / 2}$ \\
\hline- & - & - & - & - & - \\
209 & 0.34 & & very weak & & \\
218 & 0.35 & 6.8 & 8.4 & 0.46 & 0.57 \\
248 & 0.37 & 7.1 & 7.1 & 0.45 & 0.45 \\
298 & 0.41 & 6.9 & 6.9 & 0.40 & 0.40 \\
348 & 0.44 & 7.9 & 8.1 & 0.42 & 0.43 \\
398 & 0.47 & 9.5 & 9.4 & 0.48 & 0.47 \\
448 & 0.50 & 12.5 & 12.4 & 0.59 & 0.59 \\
473 & 0.52 & 12.2 & 12.1 & 0.56 & 0.56 \\
498 & 0.53 & 13.0 & 13.0 & 0.58 & 0.58
\end{tabular}

Column 2 : expected bandwidth in a classical $90^{\circ}$ rotational model calculated with $I=7.11 \times 10^{-45} \mathrm{~kg} \mathrm{~m}^{2}$. Columns 3 and 4 : measured bandwidths.

Columns 5 and 6 : bandwidths divided by $\sqrt{T}$ showing that they are not proportional whatever rotation angle is chosen.

both the width of the $\mathrm{F}_{2 \mathrm{~g}}$ spectra and its important increase with temperature $\left(^{2}\right)$. The slow variation with temperature of the frequency difference between the $E_{g}$ and $F_{2 g}$ maxima has in such a case no straightforward explanation. The experimental results suggest that the thermal expansion which decreases the intermolecular interactions could explain this effect but this is by no means the only possibility.

More discussion is certainly needed, but we believe our results show important effects caused by the combination of rotations and temperature.

\section{References}

[1] Damien, J. C., Thèse U.S.T. Lille (1978).

[2] Bee, M., AmoureuX, J. P. and Lechner, R. E., Mol. Phys. 40 (1980) 617.

[3] Lightbody, D., Sherwood, J. N. and Eldrup, M., Chem. Phys. Lett. 70 (1980) 487.

[4] Wee Yaung Lee and Slutzky, L. J., J. Phys. Chem. 79 (1975) 2602.

[5] SChÖNHerr, E., in Crystals, Vol. 2, H. C. Freyhardt, ed. (Springer, Berlin) 1980.

[6] FAKTOR, M. and GARRET, I., Growth of Crystals from the Vapour, (Chapman and Hall, London) 1974.

[7] PEG 2000 is solid at room temperature. Other compounds have been tried but the solubility of adamantane at high temperature is not an easy problem. Glycerol was a good candidate, but it creates a background in the spectra, which becomes both intense and fluctuating around $150^{\circ} \mathrm{C}$ and the signal to noise ratio consequently decreases dramatically.

[8] Absolute frequencies are not given in this paper with any degree of accuracy as it was not the purpose of the experiment. On the contrary, frequency shifts are accurate to the precision of the fit.

$\left({ }^{2}\right)$ Such a contribution should also be present in the $E_{\mathrm{g}}$ spectrum. An order of magnitude calculation based on the lifetime of the molecule in its potential well shows that this contribution is too weak to be detected under the intense normal $\mathrm{E}_{\mathrm{g}}$ spectrum. 
[9] The adamantane single crystal (grown by a sublimation method and checked through Laue $\mathrm{X}$ ray tests) was set with a fourfold axis vertical and two perpendicular twofold axes parallel to the incident beam and observation direction resp. Four different combinations can be used : 1) the incident beam is polarized vertically and analysis of the scattered light is also vertical (VV) providing an $\mathrm{A}_{1 \mathrm{~g}}+4 \mathrm{E}_{\mathrm{g}}$ spectrum ; 2) vertical polarization and horizontal analysis $(\mathrm{VH}): \mathrm{F}_{2 \mathrm{~g}}$ spectrum ; 3) $\mathrm{HV}: \mathrm{F}_{2 \mathrm{~g}}$;4) $\mathrm{HH}: 3 \mathrm{E}_{\mathrm{g}}$. The depolarization ratio measured on the $758 \mathrm{~cm}^{-1}$, A line in $\mathrm{VV}$ and VH situations is inferior to $2 \%$.

[10] Jenkins, T. E. and LeWIS, J., Spectrochim. Acta, Part A 36 (1980) 259.

[11] Both the $E_{g}$ and $F_{2 g}$ peaks decrease slightly in frequency as the temperature increases, but the $E_{g}$ peak decreases faster so that they become closer as temperature increases.

[12] Sauvajol, J. L., Thèse U.S.T. Lille (1983).

[13] We assume that the actual life time of the internal vibration is much longer than the residence time between two rotations.

[14] Yvinec, M. and Pick, R. M., J. Physique 44 (1983) 169.

[15] PICK, R. M., in Vibrational Spectroscopy of Molecular Liquids and Solids, Bratos \& Pick, eds. (Plenum Press, New York) 1980.

[16] This static inhomogeneous broadening usually decreases slightly as the temperature increases. 